\title{
Direktwahl der Ministerpräsidenten: Begründung, Ausgestaltung und Umsetzbarkeit eines Wechsels der Regierungsform in den Ländern
}

\author{
Frank Decker
}

\section{Die Renaissance der Direktwahlidee in den 1990er Jahren}

Die Regierungssysteme der deutschen Länder (den stattdessen häufig verwandten Begriff der „Bundesländer" kennt das Grundgesetz nicht) sind in der vergleichenden Politikwissenschaft als Forschungsthema lange Zeit kaum präsent gewesen. Seit zehn Jahren hat sich dies deutlich geändert. Davon zeugen neben einer Reihe von umfangreichen Studien zu Teilbereichen ${ }^{1}$ nicht zuletzt mehrere Gesamtdarstellungen, die in kurzer zeitlicher Abfolge erschienen sind. ${ }^{2}$ Das jahrzehntelange Desinteresse verwundert, wenn man bedenkt, dass sich Politologen wie Wilhelm Hennis ${ }^{3}$ und Theodor Eschenburg ${ }^{4}$ in den fünfziger und sechziger Jahren eingehend mit der Frage beschäftigt hatten, ob das parlamentarische System für die Länder die angemessene Regierungsform sei. Vom damaligen kritischen Blick ist in den neuen Publikationen wenig zu spüren. Der föderalismusbedingte Bedeutungsverlust der Landesparlamente wird von den Autoren als gegeben hingenommen und die parlamentarische Regierungsform der Länder nicht weiter in Zweifel gezogen. Dies geht soweit, dass die wegweisenden Arbeiten von Hennis und Eschenburg nicht einmal mehr im Literaturverzeichnis auftauchen (so bei Leunig und Freitag / Vatter).

Wenn die Debatte dennoch neu in Gang gekommen ist, so verdankt sich dies allein der Staatsrechtslehre, insbesondere Hans Herbert von Arnim, der sich als streitbarer Kritiker der

1 Vgl. zum Beispiel Andreas Kost (Hrsg.), Direkte Demokratie in den deutschen Ländern. Eine Einführung, Wiesbaden 2005; Herbert Schneider / Hans-Georg Wehling (Hrsg.), Landespolitik in Deutschland. Grundlagen - Strukturen - Arbeitsfelder, Wiesbaden 2006, Achim Hildebrandt I Frieder Wolf(Hrsg.), Die Politik der Bundesländer. Staatstätigkeit im Vergleich, Wiesbaden 2008; Uwe Jun I Melanie Haas / Oskar Niedermayer (Hrsg.), Parteien und Parteiensysteme in den deutschen Ländern, Wiesbaden 2008; Kerstin Völkl / Kai-Uwe Schnapp / Everhard Holtmann I Oscar W. Gabriel (Hrsg.), Wähler und Landtagswahlen in der Bundesrepublik Deutschland, Baden-Baden 2008.

2 Vgl. Markus Freitag / Adrian Vatter (Hrsg.), Die Demokratien der deutschen Bundesländer. Politische Institutionen im Vergleich, Opladen / Farmington Hills 2008; Sven Leunig, Die Regierungssysteme der deutschen Länder im Vergleich, Opladen / Farmington Hills 2007 (2. Auflage, 2012); Werner Reutter, Föderalismus, Parlamentarismus und Demokratie. Landesparlamente im Bundesstaat, Opladen / Farmington Hills 2008. Eine komprimierte Gesamtschau wurde vom Verfasser bereits 2004 vorgelegt. Vgl. Frank Decker, Die Regierungssysteme in den Ländern, in: ders. (Hrsg.), Föderalismus an der Wegscheide?, Wiesbaden 2004, S. 169 - 201. Aus demselben Jahr datiert eine umfassende Bestandsaufnahme des Landesparlamentarismus. Vgl. Siegfried Mielke / Werner Reutter (Hrsg.), Länderparlamentarismus in Deutschland. Geschichte, Struktur, Funktionen, Wiesbaden 2004.

3 Vgl. Wilhelm Hennis, Parlamentarische Opposition und Industriegesellschaft. Zur Lage des parlamentarischen Regierungssystems, in: Gesellschaft - Staat - Erziehung, 5. Jg. (1956), H. 1, S. 205 -222, wiederabgedruckt in: ders., Regieren im modernen Staat. Politikwissenschaftliche Abhandlungen I, Tübingen 1999, S. 1 - 23.

4 Vgl. Theodor Eschenburg, Parlamentarische Regierung in den Ländern, in: ders., Zur politischen Praxis in der Bundesrepublik. Kritische Betrachtungen 1957 bis 1961, München 1964, S. 223 227. 
Parteien über die Grenzen seiner Zunft hinaus einen Namen gemacht hat. ${ }^{5}$ Von Arnim brachte den Vorschlag einer Abkehr vom parlamentarischen System (mit der Direktwahl des Ministerpräsidenten als Herzstück), der bereits in den fünfziger Jahren von Theodor Eschenburg $^{6}$ als Konzept für die Verfassung des neu zu schaffenden Landes Baden-Württemberg entwickelt worden war, in den neunziger Jahren wieder ins Spiel (am prominentesten in den 1995 lancierten Thesen der „Frankfurter Intervention“). ${ }^{7}$ Ohne besonders viel öffentliche Resonanz zu erzeugen, entspann sich daraufhin eine wissenschaftliche Diskussion, an der - mit Ausnahme des Verfassers ${ }^{8}$ - ausschließlich Verfassungsrechtler teilnahmen. ${ }^{9}$ Eine gründliche wissenschaftliche Ausarbeitung des Konzepts unternahm von Arnims Schüler Jan Backmann in seiner 2007 veröffentlichten Speyerer Dissertation. ${ }^{10}$

Die Renaissance der Direktwahlidee muss vor dem Hintergrund der verfassungspolitischen Entwicklung gesehen werden, die ab Ende der achtziger Jahre in den Ländern einsetzte. Auf der einen Seite kam es zu einer flächendeckenden Reform der Kommunalverfassungen. Die Volkswahl der Bürgermeister, die bis dahin nur in Bayern und Baden-Württemberg üblich war, wurde in den anderen Ländern der alten Bundesrepublik übernommen und in den neuen Ländern von Beginn an eingeführt. Dies war gleichbedeutend mit dem Übergang von der parlamentarischen zur präsidentiellen Regierungsform. Auf der anderen Seite hielten Verfahren der direkten Demokratie ${ }^{11}$ Einzug. Wo sie nicht vorhanden waren, wurden sie

5 Aus der Reihe der zahlreichen Titel vgl. zum Beispiel: Hans Herbert von Arnim, Das System. Die Machenschaften der Macht, München 2001. Für eine kritische Auseinandersetzung mit von Arnims Parteienkritik siehe Eckhard Jesse, (Über-)Scharfe Kritik am „Versagen der Politik“. Hans Herbert von Arnims „Volksparteien ohne Volk“, in: ZPol, 19. Jg. (2009), H. 3, S. 421 - 436.

6 Vgl. Theodor Eschenburg, Verfassung und Verwaltungsaufbau des Südweststaates, Stuttgart 1952.

7 Vgl. Hans Herbert von Arnim, Wege aus der Krise des Parteienstaates. Thesen der „Frankfurter Intervention", in: Recht und Politik, 31. Jg. (1995), H. 1, S. 16 - 26.

8 Vgl. Frank Decker, Direktwahl der Ministerpräsidenten?, in: Recht und Politik, 37. Jg. (2001), H. 3, S. 152 - 160; ders., Zwischen Placebo und Erfolgsmodell. Direkte Demokratie auf der Landesebene, in: ZParl, 41. Jg. (2010), H. 3, S. 564 - 579. Obwohl der Direktwahlvorschlag in dem letztgenannten Aufsatz nur beiläufig, nämlich im Systemzusammenhang der Volksgesetzgebung erwähnt wurde, forderte er zum ersten Mal die Reaktion eines Politikwissenschaftlers heraus. Vgl. Everhard Holtmann, Direkt gewählte Ministerpräsidenten der Länder - eine kritische Folgenabschätzung der von Frank Decker in Heft 3/2010 der ZParl veröffentlichten Überlegungen, in: ZParl, 42. Jg. (2011), H. 1, S. 194 - 205. Dazu meine Entgegnung: Direktwahl der Ministerpräsidenten? Eine Entgegnung auf Everhard Holtmanns Replik in Heft 1/2011 der ZParl, in: ZParl, 42. Jg. (2011), H. 4, S. $886-890$.

9 Vgl. zum Beispiel Hans Hugo Klein, Direktwahl der Ministerpräsidenten?, in: Burkhardt Ziemske I Theo Langheid / Heinrich Wilms / Goerg Haverkate (Hrsg.), Staatsphilosophie und Rechtspolitik, München 1997, S. 573 - 587; Fred Esterbauer, Volkswahl der Regierung? Thesen zu einem demokratischeren und stabileren Regierungssystem, in: Hans Herbert von Arnim (Hrsg.), Direkte Demokratie, Berlin 1999, S. 161 - 175; Hartmut Maurer, Volkswahl des Ministerpräsidenten?, in: Heiko Faber / Götz Frank (Hrsg.), Demokratie in Staat und Wirtschaft, Tübingen 2002, S. 143 - 162; Hans Herbert von Arnim, Systemwechsel durch Direktwahl der Ministerpräsidenten, in: Arthur Benz / Heinrich Siedentopf / Karl-Peter Sommermann (Hrsg.), Institutionen in Regierung und Verwaltung, Berlin 2004, S. $371-385$.

10 Vgl. Jan L. Backmann, Direktwahl der Ministerpräsidenten. Als Kern einer Reform der Landesverfassungen, Berlin 2006.

11 Hierunter fallen zum einen Abstimmungen über Sachfragen, zum anderen Personalvoten, die außerhalb der regulären Wahlen stattfinden (Abberufung von Amtsträgern / „recall“, plebiszitäre Parlamentsauflösung). 
eingeführt, wo sie bereits bestanden, ausgebaut und ihre Anwendungsbedingungen verbessert. Dies galt sowohl für die kommunale (Bürgerbegehren / Bürgerentscheid) als auch für die Landesebene (mit der zwei- oder dreistufig ausgestalteten Volksgesetzgebung).

Ob plebiszitäre Sachentscheidungen und die Direktwahl von Amtsträgern gleichermaßen unter den Begriff „Direktdemokratie“ subsumiert werden können, ist umstritten. ${ }^{12}$ Auch über die systemischen Zusammenhänge zwischen beiden Verfahren hat man sich in der Literatur bisher keine großen Gedanken gemacht - weder in der Staatsrechtslehre noch in der Politikwissenschaft. Dabei wäre, wie weiter unten dargelegt wird, gerade das Vorhandensein eines zu Oppositionszwecken einsetzbaren Gesetzgebungsrechts des Volkes ein Grund, dem Beispiel der Kommunen zu folgen und auf der Landesebene vom parlamentarischen zum präsidentiellen System zu wechseln. Ein anderer Effekt der Volksgesetzgebung ist den Beobachtern dagegen nicht verborgen geblieben. Diese kann von den Bürgern als Hebel benutzt werden, um institutionelle Reformen notfalls in eigener Regie zu betreiben. Beim Wahlrecht und den direktdemokratischen Verfahren selbst waren die gegen die Parteien gerichteten Initiativen häufig von Erfolg gekrönt. Warum sollte das nicht irgendwann genauso bei der Direktwahl funktionieren?

Allerdings haben die hauptsächlich im Umkreis des Vereins „Mehr Demokratie“ anzusiedelnden potenziellen Initiatoren solchen Reformbestrebungen bislang kaum Interesse entgegengebracht und ihr Augenmerk stattdessen auf das Wahlrecht und die Direktdemokratie gerichtet. Lediglich in Rheinland-Pfalz kam es auf Betreiben Hans Herbert von Arnims im Jahre 2000 zu einer Initiative, die aber von ihrem Träger - den Freien Wählern - nach einer verpatzten Wahlteilnahme wieder zurückgezogen wurde.

Der bayerische Landesverband der Ökologisch-Demokratischen Partei hat jetzt einen neuen Anlauf gestartet. Die Volksinitiative für die Einführung der Direktwahl wurde Ende 2012 lanciert $^{13}$; ihr soll, wenn genügend Unterschriften zusammenkommen, ein Volksbegehren folgen.

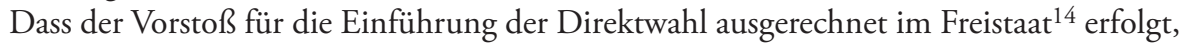
hat mehrere Gründe. Erstens ist man dort mit den plebiszitären Verfahren auf kommunaler und Landesebene gut vertraut. Zweitens gibt es mit der ÖDP und den - im Landtag vertretenen - Freien Wählern zwei relevante Parteien, die sich für die Idee einsetzen. Drittens verleiht die Konstellation der bevorstehenden Landtagswahl dem Vorhaben zusätzliche Brisanz, nachdem die SPD mit dem Münchener Oberbürgermeister Christian Ude einen populären Spitzenkandidaten als Herausforderer von Horst Seehofer nominiert hat. Und viertens haben die Bayern mit einer unangenehmen Begleiterscheinung des parlamentarischen Systems in der jüngeren Vergangenheit gleich zweimal Bekanntschaft gemacht: 2007 wurde CSU-Ministerpräsident Edmund Stoiber während der laufenden Wahlperiode von seiner

12 Zur Begriffsdiskussion vgl. Frank Decker, Regieren im „Parteienbundesstaat“. Zur Architektur der deutschen Politik, Wiesbaden 2011, S. 168 ff.

13 Der Entwurf ist einsehbar auf der Homepage der Initiative, http://www.direktwahl-ministerpräsident.de.

14 Am ehesten prädestiniert für eine Reform erscheinen weiterhin die Stadtstaaten, deren Affinität zur kommunalen Politik am stärksten ausgeprägt ist. So wäre zum Beispiel die Dreieinhalbmillionen-Stadt Berlin automatisch in den Geltungsbereich der „präsidentiellen“ Kommunalverfassung eines gemeinsamen Bundeslandes Berlin-Brandenburg gelangt, wenn die Fusion mit dem Nachbar 1996 geklappt hätte. 
Partei gestürzt, für die er bei der Landtagswahl 2003 noch ein Rekordwahlergebnis erzielt hatte; und 2008 erhielt das Land einen Regierungschef, der bei der Wahl als Spitzenkandidat gar nicht angetreten war, als Seehofer den wegen der hohen CSU-Verluste zurückgetretenen Stoiber-Nachfolger Günther Beckstein kurzerhand ersetzte.

Der nun vorgelegte Reformvorschlag der bayerischen ÖDP wurde auf Bitte der Initianten von Hans Herbert von Arnim zusammen mit dem Verfasser erarbeitet. Auf dieser Basis soll hier ein „Idealmodell“ der Direktwahl der Ministerpräsidenten skizziert werden.

\section{Die "falschen" Argumente für die Direktwahl: Mehr Demokratie und Gewaltenteilung}

Die Direktwahlbefürworter aus der Staatsrechtslehre argumentieren ziemlich verquer. Damit leisten sie der Gegenseite ungewollt Schützenhilfe und machen es ihr leichter als nötig, den Reformvorschlag zurückzuweisen. Die Gründe, die für den Wechsel zum Präsidentialismus hauptsächlich ins Feld geführt werden, könnten normativ nicht zwingender sein. Das präsidentielle System, so heißt es, sei demokratischer, weil erstens durch die Direktwahl die Legitimationskette bei der Bestellung der Regierung entscheidend verkürzt werde („InputLegitimation“). Zweitens sei es auch unter Regierungsgesichtspunkten überlegen, indem es dazu beitrage, parteiliche oder Partikularinteressen zugunsten des „Gemeinwohls“ zurückzudrängen („Output-Legitimation“). Und drittens realisiere es die Idee der Gewaltenteilung besser, die im parlamentarischen System durch die politische Fusion von Regierung und Parlamentsmehrheit nur unvollständig bestehe. ${ }^{15}$

Aus politikwissenschaftlicher Sicht stehen alle drei Begründungen auf schwachen Füßen. Sie sind nicht nur empirisch unhaltbar, wie die umfangreiche Forschung zum Vergleich parlamentarischer und präsidentieller Regierungssysteme zeigt, sondern auch normativ. Was die Regierungseffizienz angeht, sieht die Mehrzahl der Autoren die Vorteile eher auf der Seite des parlamentarischen Systems, das durch die Verschränkung von Regierung und Parlamentsmehrheit einerseits eine größere Konsistenz des Regierens ermögliche und andererseits über die Kombination von Misstrauensvotum und Parlamentsauflösung Vorkehrungen treffe, dass jederzeit eine regierungsfähige Mehrheit vorhanden sei beziehungsweise neu zustande komme. Das präsidentielle System, in dem sich Exekutive und Legislative in ihrem wechselseitigen Bestand nichts anhaben könnten, tendiere demgegenüber zu Blockaden. ${ }^{16}$

Auch bei der Input-Legitimation ist der Präsidentialismus nicht zwangsläufig überlegen. Dem Pluspunkt der Direktwahl steht hier erstens das Problem gegenüber, dass der Präsident seine Regierungsmacht mit dem Kongress teilen muss. Der Wähler kann im präsidentiellen System folglich ebenso wenig eine klare Richtungsentscheidung treffen wie in jenen parlamentarischen Systemen, in denen die Regierung von mehreren Parteien gemeinsam gebildet wird. Zweitens unterliegt die demokratische Verantwortlichkeit des „chief executive“ Zweifeln, wenn dieser während seiner Amtszeit sankrosankt ist, also weder vom Kongress noch

15 Für eine umfassende Entfaltung der drei Argumente vgl. Jan L. Backmann, a.a.O. (Fn. 10), S. $123 \mathrm{ff}$.

16 Vgl. Juan J. Linz, The Perils of Presidentialism, in: Journal of Democracy, 1. Jg. (1990), H. 1, S. $51-69$. 
vom Volk, das ihn bestellt hat, aus politischen Gründen abberufen werden kann. Auch die Amtszeitbegrenzung ist in dieser Hinsicht prekär. ${ }^{17}$ Und drittens muss hinter die Nachfolgeregelung ein Fragezeichen gesetzt werden. Wenn der Präsident in den USA während der Amtszeit stirbt, zurücktritt oder durch ein Impeachment-Verfahren abgesetzt wird, rückt der auf seinem „Ticket“ lediglich mitgewählte Vizepräsident automatisch nach. Der Unterschied zu den parlamentarischen Systemen, wo die Wechsel an der Regierungsspitze meistens ebenfalls ohne vorherige Neuwahlen stattfinden, ist also nicht besonders groß.

Das Gewaltenteilungsargument hat auf den ersten Blick mehr für sich. Dass die präsidentielle Regierungsform dem klassischen Gewaltenteilungskonzept von Montesquieu näher kommt als die parlamentarische, wird kaum jemand bestreiten. Eine normative Höherwertigkeit lässt sich daraus aber nicht ableiten. Man mag es als Vorteil betrachten, dass die Parlamente, weil sie die Regierung nicht bestellen und im Amt halten, ihre Macht im präsidentiellen System primär über die Gesetzgebung entfalten. Die Abgeordneten regieren also tatsächlich mit, was sie in den parlamentarischen Systemen nicht tun dürfen oder können. Diese haben die klassische Gewaltenteilung durch das Gegenüber von regierender Mehrheit und Opposition ersetzt. Die Vertreter der Mehrheit überlassen der von ihnen getragenen Regierung dabei weitgehend die Initiative, während die Minderheit ganz auf ihre Kritik- und Alternativfunktion verwiesen ist, die sie mit dem Ziel wahrnimmt, die Regierung nach der kommenden Wahl abzulösen.

Ein solches System der Gewaltenteilung, das historisch auf eine ähnlich stolze Tradition zurückblicken kann, ist nicht besser oder schlechter als das gewaltentrennende Modell des Präsidentialismus, auch wenn es für die Parlamentarier vielleicht größere Frustrationen birgt. Dies gilt umso mehr, als es innerhalb der parlamentarischen Systeme, was die institutionelle Ausgestaltung und Praxis des „neuen Dualismus“ 18 betrifft, ein denkbar weites Spektrum gibt. In annähernder Reinform existiert das Alternierungsmodell heute ohnehin nur noch in Großbritannien (und auch hier mit abnehmender Tendenz), während der Gegensatz zwischen Regierung und Opposition in den übrigen Ländern durch konsensdemokratische Elemente in mannigfacher Weise durchbrochen wird. Dies kann soweit gehen, dass die parlamentarischen Systeme in ihrer Funktionsweise starke Übereinstimmungen mit dem Präsidentialismus aufweisen (wie etwa beim skandinavischen Minderheitsparlamentarismus). ${ }^{19}$

17 „[T] here is no way to hold accountable a president who cannot be presented for reelection. Such a president can neither be punished by the voters by defeat nor rewarded for success by reelection with the same or larger vote than in the previous election." Juan J. Linz, Presidential or Parliamentary Democracy: Does It Make a Difference?, in: ders. / Arturo Valenzuela (Hrsg.), The Failure of Presidential Democracy, Baltimore / London 1994, S. 3 - 87, S. 12.

18 Als einer der Ersten begann in den 1960er Jahren Winfried Steffani eine dem parlamentarischen Regierungssystem geeignete Gewaltenteilungstheorie zu entwickeln. Vgl. ders., Gewaltenteilung im demokratischen Verfassungsstaat, in: Günther Rüther (Hrsg.), Politik und Gesellschaft in Europa, Köln 1994, S. 48 - 57; ders., Grundzüge einer politologischen Gewaltenteilungslehre, in: ders., Parlamentarische und präsidentielle Demokratie. Strukturelle Aspekte westlicher Demokratien, Opladen 1979, S. 9 - 36 (erste Fassung in: PVS, 3. Jg. (1962), H. 3, S. 256 - 282); beide Aufsätze neu abgedruckt in: ders. (Hrsg.), Gewaltenteilung und Parteien im Wandel, Opladen 1997, S. $18-26$, S. $27-55$.

19 Vgl. Nicole Bolleyer, Minderheitsparlamentarismus - eine akteurszentrierte Erweiterung der Parlamentarismus-Präsidentialismustypologie, in: ZPol, 11. Jg. (2001), H. 4, S. 1519 - 1546. 
Die Diskussion kann an dieser Stelle abgebrochen werden, denn wie immer man es dreht und wendet: Die Behauptung einer Überlegenheit des präsidentiellen Systems unter Demokratie- und Gewaltenteilungsgesichtspunkten lässt sich nicht aufrecht erhalten. Mit ihr begeben sich die Reformbefürworter zudem auf argumentatives Glatteis. Würde ihre These stimmen, müsste die Einführung des präsidentiellen Systems konsequenterweise ja auch (und gerade) auf nationaler Ebene gefordert werden und nicht nur für die Länder. Die Gegner hätten insofern Recht, wenn sie vor einem „Kamineffekt“ warnen. ${ }^{20}$ Sei die Direktwahl in den Ländern erst einmal eingeführt, so die Befürchtung, würden gleichlautende Bestrebungen früher oder später auch im Bund laut. Dass die Sorge nicht ganz unbegründet ist, belegt die Verfassungsentwicklung im Bereich der direkten Demokratie, deren Ausbau in den Ländern aus Sicht der Befürworter zugleich als „Blaupause“ für die Bundesebene dienen soll. Auch hier führen Vorstellungen einer vermeintlichen normativen Höherwertigkeit der Plebiszite zu falschen systemischen Schlussfolgerungen. ${ }^{21}$

\section{Die „richtigen“ Argumente: Bessere Passform des Regierungssystems, mehr Eigenständigkeit der Länder und Aufwertung des Föderalismus}

Die „richtige“ Begründung für die Einführung der Direktwahl muss bei der Eigenart der Landespolitik ansetzen. Sie lässt sich in drei Argumente unterteilen: Erstens passt das präsidentielle System besser zu den Aufgaben, die die Länder zu erfüllen haben; diese sind überwiegend verwaltungsbezogen und legen daher einen konsensorientierten Politikstil nahe. Zweitens trägt es der Einführung und dem Ausbau der direktdemokratischen Verfahren Rechnung, durch die sich die Funktionsweise des parlamentarischen Regierungssystems in den Ländern verändert hat. Und drittens führt die Einführung des Präsidentialismus zu einer stärkeren Betonung der Eigenständigkeit der Länder gegenüber dem Bund, die den Föderalismus insgesamt aufwertet.

(1) Das erste Argument knüpft nahtlos an die älteren Arbeiten von Hennis und Eschenburg zum Landesparlamentarismus an. Hennis hatte die Eigenart der Landespolitik seinerzeit mit der Feststellung auf den Punkt gebracht, dass es „keinen christlich-demokratischen Straßenbau und keine sozialdemokratische Wasserwirtschaft" 22 gebe. In dieser Zuspitzung war das zwar verfehlt, da auch verwaltungsbezogene Aufgaben nicht generell unpolitisch sind und dadurch dem Parteienwettbewerb zugänglich bleiben. Dennoch bleibt es richtig, dass zwischen Landes- und Bundespolitik im deutschen Föderalismus ein markanter Unterschied besteht. Während das Gros der Gesetzgebungsbefugnisse beim Gesamtstaat liegt, sind die Länder vor allem mit der Durchführung der Gesetze betraut. Allein im Bildungsbereich verfügen sie noch über substanzielle eigene Gestaltungsmöglichkeiten, die sie durch die 2006 beschlossene Föderalismusreform sogar weiter ausbauen konnten. Allerdings empfiehlt sich

20 So Everhard Holtmann, a.a.O. (Fn. 8), S. 201.

21 Vgl. Frank Decker, Der Irrweg der Volksgesetzgebung. Warum die direkte Demokratie in den Ländern kein Vorbild für die Bundesebene sein kann, in: Zeitschrift für Staats- und Europawissenschaften (ZSE), 9. Jg. (2011), H. 4, S. 473 - 500.

22 Wilhelm Hennis, a.a.O. (Fn. 3), S. 16. 
aus Gründen der Planungssicherheit auch hier ein Zusammenwirken der Parteien, da Entscheidungen über die Struktur des Schul- und Hochschulwesens weit in die Zukunft hineinwirken. Die starke ideologische Aufladung der Bildungspolitik stand einem solchen Konsens lange Zeit im Wege.

In allen anderen Bereichen weisen die Länder gemessen an ihrem Aufgabenzuschnitt eine größere Nähe zur kommunalen als zur Bundespolitik auf. ${ }^{23}$ Folglich liegt natürlich die Frage nahe, warum sie sich nicht auch bei der Gestaltung ihrer Regierungssysteme an der „unteren Ebene“ orientieren. Für das Festhalten am parlamentarischen Regierungssystem wird häufig angeführt, dass sich die Länder an einer Stelle von den Kommunen tatsächlich abheben: durch ihre Mitwirkungsrechte an der Bundesgesetzgebung, die die Landesregierungen über den Bundesrat ausüben. Daran würde sich aber bei einer Direktwahl gar nichts ändern. Im Gegenteil: Die Abkehr von der parlamentarischen Regierungsform könnte auch in dieser Hinsicht von Vorteil sein, indem sie die Inflationierung der Enthaltungen zurückdrängt, die im heutigen System durch die „gemischten“ Koalitionen verursacht werden. Statt sich in den Automatismus der Nicht-Entscheidung zu flüchten, wären die Landesregierungen gezwungen, sich auf ihr Abstimmungsverhalten politisch zu verständigen. ${ }^{24}$

(2) Vergleicht man die institutionellen Strukturen der Landes- und Bundespolitik miteinander, ergibt sich ein mehrdeutiger Befund. Auf der einen Seite bleiben hergebrachte Unterschiede, die auf die Statusdifferenz zwischen Glied- und Gesamtstaat zurückgehen. So kennen die Länder weder eine zweite Gesetzgebungskammer noch ein vom Regierungschef abgetrenntes Staatsoberhaupt. Letzteres hat wiederum die Einführung eines Selbstaufösungsrechts der Parlamente in allen und das Fehlen einer Vertrauensfrage in den meisten Landesverfassungen zur Folge. Die parlamentarischen Systeme der Gliedstaaten sind damit von ihrer Grundstruktur her monokratischer beziehungsweise mehrheitsdemokratischer als dasjenige des Bundes. Auf der anderen Seite haben die Länder diese Mehrheitslogik noch verstärkt, indem sie sich im Kernbereich des parlamentarischen Systems - bei der Organisation des Verhältnisses von Parlament und Regierung -, dem Modell des Grundgesetzes anpassten. Konstitutionelle Eigenheiten wie zum Beispiel das Kollegialprinzip der Regierungen in den Hansestädten wurden dabei im Zuge von Verfassungsreformen aufgegeben. Ein ähnlicher Angleichungsprozess erfolgte beim Wahlrecht, wo zwölf von sechzehn Ländern das Zweistimmensystem mit Fünf-Prozent-Sperrklausel übernahmen, das auf nationaler Ebene 1953 eingeführt worden war.

Eine gegenläufige Entwicklung setzte ab Mitte der achtziger Jahre mit dem Ausbau der direktdemokratischen Verfahren ein. Diese waren schon in der Weimarer Zeit als Gegengewicht zum Mehrheitsabsolutismus konzipiert worden, den die Verfassungsgeber als Folge des parlamentarischen Systems befürchteten. Die Volksrechte sollten damit auch in die

23 Dies lässt sich am geringen Umfang ihrer legislativen Tätigkeit ablesen: Der Bund verabschiedet in einer Wahlperiode im Schnitt etwa viermal so viele Gesetze wie die einzelnen Landtage. Gleichzeitig machen die Länder den Kommunen auch unmittelbar Konkurrenz. Weil die großen Komplexe der Landesgesetzgebung seit Langem abgearbeitet sind, stoßen sie immer mehr in solche (Rand)gebiete der Gesetzgebung vor, deren Regelung man genauso gut der lokalen Ebene überlassen könnte. Vgl. Roland Sturm, Föderalismus in Deutschland, Opladen 2001, S. 73.

24 Vgl. Everhard Holtmann, a.a.O. (Fn. 8), S. 202. Zum Problem der Enthaltungen im Zusammenhang mit den Abstimmungsregeln des Bundesrates vgl. Frank Decker, Wenn die Populisten kommen. Beiträge zum Zustand des Parteiensystems und der Demokratie, Wiesbaden 2013, S. 207 ff. 
Rolle des auf der gliedstaatlichen Ebene nicht vorhandenen separaten Staatsoberhauptes hineinschlüpfen. ${ }^{25}$ Die vorgrundgesetzlichen Landesverfassungen nahmen dieses Modell wieder auf. In der Praxis spielten die direktdemokratischen Verfahren aber keine Rolle, nachdem sich auf der Bundesebene die betont anti-plebiszitäre Konzeption des Grundgesetzes durchgesetzt hatte. In den nach Gründung der Bundesrepublik verabschiedeten Landesverfassungen wurden sie erst gar nicht eingeführt. Die Regierungssysteme der beiden staatlichen Ebenen wiesen deshalb auch in der Funktionsweise bis zum Beginn des plebiszitären Reformprozesses in den Ländern wenige Unterschiede auf.

Die Durchsetzung des Parlamentarismus in der Bundesrepublik führte dazu, dass das konstitutionelle Gleichgewichtsdenken auch innerhalb der Staatsrechtslehre zurückgedrängt wurde. ${ }^{26}$ Symptomatisch für die normative Anerkennung des „neuen Dualismus“ steht zum Beispiel die nachträgliche Einführung der „Oppositionsklauseln“ in die meisten Landesverfassungen. Vor diesem Hintergrund hätte man die Brisanz der seit den achtziger Jahren eingeschlagenen Verfassungsentwicklung eigentlich sehen müssen. Die Bundesländer kennen zwar im Unterschied zur Schweiz kein plebiszitäres Veto (dort fakultatives Referendum genannt), sondern nur die „positive“ Volksgesetzgebung. Auch diese gibt den Bürgern aber die Möglichkeit, ein von der regierenden Mehrheit geplantes oder beschlossenes Gesetz zu Fall zu bringen. ${ }^{27}$ Damit wird die Funktionslogik des parlamentarischen Systems untergraben. Die parlamentarische Opposition ist dann nicht mehr auf ihre Alternativfunktion beschränkt, sondern kann das Gestaltungsmonopol der Regierung auf plebiszitärem Wege durchkreuzen. Diese wiederum wird darauf reagieren, indem sie etwaige Widerstände gegen ihre Vorhaben schon vorab berücksichtigt. Die direktdemokratischen Verfahren wirken also in Richtung Konsens. In der Schweiz hat das zur Herausbildung eines Konkordanzsystems geführt, in dem der Gegensatz von Regierung und Opposition auch förmlich aufgehoben ist.

Dass den Verfassungsgebern das Problem durchaus bewusst ist, zeigt sich an der restriktiven Ausgestaltung der plebiszitären Verfahren, deren Anwendung durch Themenausschlüsse, Quoren und sonstige Regelungen starken Einschränkungen unterliegt. Die Direktdemokratie wird dadurch zu einem permanenten verfassungsrechtlichen und -politischen Konfliktherd. Man streitet sich nicht im Rahmen der direkten Demokratie über Inhalte, sondern über die direkte Demokratie selbst. An dieser Stelle kommt die präsidentielle Reformoption ins Spiel. Mit ihr könnte das Pferd gewissermaßen von hinten aufgezäumt werden. Statt die Volksgesetzgebung dem bestehenden parlamentarischen System anzupassen, was auf einen Dauerstreit um die richtige Ausgestaltung hinausläuft, würde die Regierungsform auf das bestehende System der Direktdemokratie zugeschnitten. Die Volksrechte bekämen auf diese Weise einen breiteren Spielraum und könnten sich innerhalb des repräsentativen Systems als alternativer Pfad der Gesetzgebung leichter zur Geltung bringen.

25 Auf der Reichsebene wurden die Volksrechte zusätzlich zum Präsidentenamt eingeführt. Dies stellte das Ergebnis eines Verfassungskompromisses dar, um die linken Parteien für das Modell eines mit starken Rechten ausgestatteten Staatsoberhauptes zu gewinnen.

26 Vgl. Frank Decker, Konstitutionelles versus parteiendemokratisches Parlamentarismusverständnis? Bemerkungen zu einer überholten Dichotomie, in: Stefan Brink / Heinrich Amadeus Wolff(Hrsg.), Gemeinwohl und Verantwortung, Berlin 2004, S. 533 - 554.

27 Nach Auswertungen des Verfassers trifft dies auf rund zwei Drittel der in den Ländern bisher eingeleiteten Volksbegehren zu. 
Direktdemokratische Verfahren „von unten“ sind im präsidentiellen System besser aufgehoben als im parlamentarischen ${ }^{28}$, weil die Regierungsmacht hier ohnehin zwischen Exekutive und Legislative geteilt ist. Opposition wird fallweise ausgeübt; es gibt keine dauerhaft festgefügten Koalitionen. Tritt das Volk als weiterer Vetoakteur hinzu, wird die Funktionslogik dieses Systems nicht prinzipiell gestört, auch wenn die Komplexität des Verhandlungsprozesses nochmals zunimmt. Die plebiszitären Verfahren können sogar eine ausgesprochen nützliche Rolle spielen, wenn sie dazu beitragen, Blockaden zwischen Präsident und Parlament aufzulösen - diese gehören wie gesehen zu den Hauptschwächen des Präsidentialismus.

Der Wechsel der Regierungsform drängt sich als Reformoption auch deshalb auf, weil es den Ländern kaum möglich sein wird, die plebiszitären Instrumente zurückzudrängen oder gar abzuschaffen. Die Entwicklung dürfte eher in Richtung einer weiteren Erleichterung der Verfahren gehen, die den potenziellen Konflikt zwischen parlamentarischer und Volksgesetzgebung verschärft. Mit Blick auf die Bundesebene könnte sich ein Systemwechsel ebenfalls als segensreich erweisen, weil er den Druck vermindern würde, die Verfahren der Direktdemokratie in das Grundgesetz zu übernehmen. Denn so wie das Vorhandensein der Volksgesetzgebung in den Ländern Zweifel an der Sinnhaftigkeit der dortigen parlamentarischen Regierungsform weckt, so weckt das vorhandene parlamentarische Regierungssystem im Bund Zweifel an der Sinnhaftigkeit einer dort einzuführenden Volksgesetzgebung. ${ }^{29}$

(3) Eine konsequente Abschichtung der Regierungssysteme der beiden staatlichen Ebenen würde den unitarischen Tendenzen im deutschen Föderalismus entgegenwirken. Die starke bundespolitische Überlagerung der Landespolitik erweist sich vor allem bei den Landtagswahlen als Problem, wo die Regierungen häufig für Leistungen und Versäumnisse belohnt oder bestraft werden, an deren Zustandekommen sie unmittelbar gar keinen Anteil haben. ${ }^{30}$ Die Ursachen dafür liegen nicht nur in der föderalen Aufgabenverteilung, die bei den Bürgern zu Recht den Eindruck entstehen lässt, dass über ihre materielle Lebenswirklichkeit primär auf der Bundesebene entschieden wird. Sie gehen auch auf die institutionelle Gleichförmigkeit der Landes- und Bundespolitik zurück. Weil die Länder das parlamentarische

28 Die These wird durch die tatsächliche empirische Verbreitung gestützt. Auf der nationalen Ebene kennt man die Initiative zwar nicht in den USA, dafür aber in vielen lateinamerikanischen Staaten. Auch die Schweiz, das Land mit der am stärksten ausgebauten Direktdemokratie überhaupt, stellt von der Grundstruktur her ein präsidentielles System dar. In den parlamentarischen Demokratien spielen die von unten eingeleiteten Verfahren dagegen keine große Rolle. Sieht man von einigen ostmitteleuropäischen Staaten ab, die die Volksrechte nach 1989 eher im Übereifer denn aus einer wirklichen Kenntnis ihrer systemischen Wirkungen heraus eingeführt haben, sind sie - in der abgeschwächten Form der Vetoinitiative - nur in Italien vorgesehen.

29 Vgl. Frank Decker, a.a.O. (Fn. 12), S. 186 ff.

30 Vgl. ders., Höhere Volatiliät bei Landtagswahlen? Die Bedeutung bundespolitischer „Zwischenwahlen“, in: Eckhard Jesse / Roland Sturm (Hrsg.), Bilanz der Bundestagswahl 2005, München 2006, S. 273 ff. Siehe auch den Schwerpunkt in Heft 3/2007 der ZParl: Oscar W. Gabriel I Everhard Holtmann, Ober sticht Unter? Zum Einfluss der Bundespolitik auf Landtagswahlen: Kontext, theoretischer Rahmen und Analysemodelle, S. 445 - 462; Kai-Uwe Schnapp, Landtagswahlen und Bundespolitik: immer noch eine offene Frage? Neue Antworten im Ländervergleich auf Aggregatdatenbasis, S. 463 - 480; Kerstin Völkl, Welchen Einfluss hat die Bundespolitik auf die Wahlentscheidung der Bürger bei Landtagswahlen? Eine Analyse von Individualdaten im Bundesländer- und Zeitvergleich, S. $480-491$. 
System des Grundgesetzes bis ins Detail nachahmen, brechen sich die Strukturen des bundespolitischen Parteienwettbewerbs auf die gliedstaatliche Ebene herunter. Damit unterliegt auch die Koalitions- und Regierungsbildung denselben Gesetzmäßigkeiten. Welche absurden Konsequenzen das haben kann, zeigte sich zum Beispiel nach der Landtagswahl in Hessen 2008, als die Republik über mehrere Monate von der Debatte in Atem gehalten wurde, ob die SPD-Spitzenkandidatin Andrea Ypsilanti sich mithilfe der Linken zur Ministerpräsidentin wählen lassen dürfe. Die Schockwellen, die davon ausgingen, sollten am Ende sogar den SPD-Bundesvorsitzenden Kurt Beck das Amt kosten. Dass eine Mehrheitsbildung unter präsidentiellen Vorzeichen ähnliche Aufmerksamkeit auf sich ziehen könnte, erscheint kaum vorstellbar. Eine Abkehr vom parlamentarischen System würde die Eigenständigkeit der Landespolitik also - unabhängig von der Kompetenzverteilung - automatisch stärker hervorheben.

\section{Probleme der institutionellen Ausführung}

Die Einführung des präsidentiellen Systems ist keine leichte Prozedur, da sie umfängliche Verfassungsänderungen erforderlich macht. Die Herausforderung besteht darin, die neu einzubringenden präsidentiellen Elemente mit den übernommenen und / oder zu modifizierenden parlamentarischen Elementen in eine angemessene Balance zu bringen. Dabei müssen die Gesetze der Pfadabhängigkeit beachtet werden. Weil es sich um keine konstitutionelle Neugründung handelt, sondern um eine Reorganisation im Rahmen bestehender Verfassungen, kann das System nicht auf der „grünen Wiese“ völlig neu errichtet werden. Auch die Einführung eines präsidentiellen Systems in Reinform kommt deshalb wohl kaum in Frage. Regelungsbedürftig sind vor allem folgende Punkte:

- die Modalitäten der Wahl des Ministerpräsidenten im Zusammenhang mit der Wahl des Landtags;

- die Amtsdauer des Ministerpräsidenten und die Möglichkeiten seiner Abwahl im Zusammenhang mit der Abwahl beziehungsweise Auflösung des Landtags;

- die Bestellung des Stellvertreters des Ministerpräsidenten und der Minister beziehungsweise des Kabinetts;

- die legislativen Kompetenzen in Verbindung mit der Ressourcenausstattung;

- die Vereinbarkeit beziehungsweise Unvereinbarkeit von Regierungsamt und Parlamentsmandat.

Im Kontext der anzustrebenden Reform nicht unmittelbar relevant sind folgende Punkte, die deshalb - auch aus praktischen Gründen der bei einer Überfrachtung erschwerten Durchsetzbarkeit - ausgeklammert werden beziehungsweise späteren Reformvorhaben vorbehalten bleiben könnten:

- die Modalitäten der Landtagswahl (Sperrklausel und Personalisierung des Verhältniswahlsystems) und

- der Status des Landtags beziehungsweise der Abgeordneten (Vollzeit- oder Teilzeitparlament).

Eine möglichst schlanke Lösung empfiehlt sich auch, damit die Bürger, die die Reform begehren und ihr am Ende mehrheitlich zustimmen müssen, von der ohnehin schon komplexen Materie nicht überfordert werden. 


\subsection{Wahl des Ministerpräsidenten}

Herzstück der Reform ist die Abschaffung des heutigen parlamentarischen Misstrauensvotums, an dessen Stelle die Direktwahl treten würde. Dabei müssten einerseits das Wahlverfahren (ein- oder zweistufig) sowie der Wahlzeitpunkt (zusammen mit der Wahl des Landtags oder von ihr getrennt) und andererseits die Nachfolgeregelung (Neuwahl oder Stellvertreterlösung) sowie eine mögliche Amtszeitbegrenzung in der Verfassung festgelegt werden.

Die Direktwahl eines Kandidaten mit lediglich relativer Mehrheit wäre unter demokratischen Gesichtspunkten fragwürdig. Der Ministerpräsident muss also, um ins Amt zu gelangen, mehr als die Hälfte der abgegebenen und gültigen Stimmen auf sich vereinigen. Steht dem Wähler nur eine Stimme zu, ist unter den Bedingungen eines sich weiter ausdifferenzierenden Vielparteiensystems kaum zu erwarten, dass diese Mehrheit von einem Kandidaten erreicht wird. Um zu einer Entscheidung zu gelangen, ist deshalb entweder ein Präferenzstimmensystem erforderlich, bei dem der Wähler eine Reihung der Kandidaten vornehmen kann: Die Präferenzstimmen würden dann nach Ausscheiden der jeweils am schlechtesten platzierten Kandidaten auf die anderen Bewerber umverteilt. Dieses - unter anderem in Australien praktizierte - System hat den Vorteil, dass es nur einen Wahlgang erfordert, der zeitgleich mit der Parlamentswahl stattfinden würde. Es ist der deutschen Tradition aber fremd, so dass sich hierzulande eher das Verfahren der Stichwahl anbietet, das auf kommunaler Ebene bereits bei den Bürgermeisterwahlen praktiziert wird: Dabei treffen die beiden Bewerber mit den höchsten Stimmenzahlen in einem zweiten Wahlgang erneut aufeinander.

Die Wahl zum Landtag sollte zeitgleich mit dem ersten Wahlgang stattfinden, die gegebenenfalls notwendige Stichwahl 14 Tage später. Durch die Synchronisierung von Landtagsund Ministerpräsidentenwahl wird die Wahrscheinlichkeit parteipolitisch gleichgerichteter Mehrheiten erhöht. Eine Zusammenlegung der Landtagswahl mit der ersten Runde der Wahl des Ministerpräsidenten statt mit der Stichwahl erscheint zweckmäßiger, weil man dadurch möglicherweise einen Wahlgang einspart (wenn es bereits bei der ersten Runde zu einer ausreichenden Mehrheit kommt). Dies dürfte sich auf die Wahlbeteiligung positiv auswirken. Darüber hinaus - und noch wichtiger - erleichtert sie das Zustandekommen einer regierungsfähigen Mehrheit insofern, als die aus der Landtagswahl siegreich hervorgegangenen (und untereinander koalitionsbereiten) Parteien Absprachen treffen können, welchen Kandidaten sie ihren Anhängern zur Wahl in der zweiten Runde empfehlen.

\subsection{Amtsdauer, Abwahl und Landtagsauflösung}

Das Nichtvorhandensein eines parlamentarischen Abberufungsrechts ist Kern des präsidentiellen Systems. Im Wegfall des Misstrauensvotums und dessen Ersetzung durch die Direktwahl liegt allerdings zugleich ein demokratiepolitisches und verfassungsrechtliches Problem, da so die Entfernung eines unverantwortlich handelnden Amtsinhabers erschwert beziehungsweise nur über den Umweg eines „Impeachment“- oder Amtsanklageverfahrens möglich ist. Diese Asymmetrie von direktdemokratischer Bestellung und nicht-vorhandener Abberufbarkeit ist verfassungssystematisch nur schwer zu rechtfertigen. Deshalb sollte der Landtag die Möglichkeit bekommen, eine Abberufung des Ministerpräsidenten auch aus 
politischen Gründen zu beantragen, allerdings unter höheren Hürden als beim normalen parlamentarischen Misstrauensvotum. Erstens bedarf es für den Antrag einer Zweidrittelmehrheit, und zweitens liegt die Entscheidung über den Antrag beim Volk. ${ }^{31}$ Letzteres stellt nicht nur die Symmetrie von Wahl und Abwahl wieder her, sondern passt auch zu den in den Landesverfassungen enthaltenen sonstigen plebiszitären Instrumenten. In der Bundesrepublik sehen eine Reihe von Kommunalverfassungen ein solchermaßen „kombiniertes“ Abwahlverfahren vor, während der in etwa der Hälfte der US-amerikanischen Bundesstaaten verbreitete „recall“ nicht nur die Letztentscheidung, sondern auch die Antragsbefugnis dem Volk überantwortet. Mit Blick auf den intendierten Gleichklang zwischen Ministerpräsident und Landtagsmehrheit scheint das kombinierte Verfahren im deutschen Kontext zweckmäßiger.

Lehnt das Volk die vom Landtag beantragte Abwahl ab, gilt dies einerseits als Neuwahl des Ministerpräsidenten. Andererseits zieht es eine Auflösung und Neuwahl des Landtags nach sich ${ }^{32}$, was zugleich die Abschaffung des bisherigen Selbstauflösungsrechts bedingt. Auch ein zusätzliches plebiszitäres Parlamentsauflösungsrecht, das heute in sieben der 16 Bundesländer besteht, wäre unter diesen Umständen entbehrlich. Die Amtszeiten von Regierung und Parlament blieben damit weiter synchron. Durch das Risiko der Auflösung soll gewährleistet werden, dass der Landtag einen Abberufungsantrag nur aus triftigem Grund stellt. Darunter können aber eben nicht nur Gesetzesverstöße oder schwere moralische Vergehen fallen wie beim „Impeachment“, sondern auch politische Fehlleistungen des Ministerpräsidenten.

Der Ministerpräsident wird auf fünf Jahre gewählt; seine Amtsperiode ist also genauso lang wie die des Landtags. Endet sie vorzeitig durch Rücktritt, Abwahl oder Tod, muss die Nachfolge geregelt sein. Dafür gibt es im Prinzip zwei Möglichkeiten: Entweder findet für den Rest der Legislaturperiode eine Neuwahl des Ministerpräsidenten statt (als „special election“). Oder der Stellvertreter des Ministerpräsidenten rückt automatisch in das höchste Amt auf. Die letztgenannte Lösung würde dem Vorbild der USA folgen. Unter Demokratiegesichtspunkten ist sie vertretbar, weil der Vizepräsident dort in der Präsidentschaftswahl auf dem „ticket“ des Präsidenten mitgewählt wird. Eine solche Konstruktion dürfte auf die Bundesrepublik schwerlich übertragbar sein. Hier wäre es besser, die vorhandene Regelung beizubehalten, wonach der Ministerpräsident selbst nach der Wahl aus dem Kreise seiner Minister einen Stellvertreter bestimmt (siehe unten). Dies würde ihm auch die Freiheit geben, einen Kandidaten einer anderen Partei zu nominieren, der zur Bildung einer regierungsfähigen Mehrheit im Landtag beitragen könnte. Ein lediglich ernannter Ministerpräsident wäre aber zweifellos mit einem demokratischen Makel behaftet, der auch mit Verweis auf den Ausnahmecharakter des vorzeitigen Ausscheidens nicht geheilt werden

31 Der Verzicht auf ein erhöhtes Quorum war einer der Kardinalfehler der Verfassungsreform in Israel, das 1992 die Direktwahl des Premierministers als erstes Land auf der nationalen Ebene im Rahmen seines parlamentarisch verfassten Regierungssystems eingeführt hatte. Vgl. Frank Decker, Direktwahl des Premierministers. Das Scheitern des präsidentiell-parlamentarischen Systems in Israel, in: ZfP, 53. Jg. (2006), H. 3, S. 256 - 283.

32 Eine identische Regelung für die Abwahl des Reichspräsidenten war in Art. 43 der Weimarer Reichsverfassung vorgesehen. Sie wurde von Theodor Eschenburg im nicht ausgeführten Entwurf für die Verfassung des 1952 neu geschaffenen Bundeslandes Baden-Württemberg übernommen. Vgl. ders., a.a.O. (Fn. 6), S. 66. 
könnte. Daher erscheint es zweckmäßig, die Ernennung des Stellvertreters an ein zustimmendes Votum des Landtags zu binden. ${ }^{33}$

Die demokratisch sauberere Neuwahllösung hätte auf der anderen Seite den Nachteil, dass ein direkt gewählter Ministerpräsident unter Umständen nur für eine sehr kurze Restzeit der Wahlperiode amtierte, es sei denn, man wollte die Gleichzeitigkeit der Amtszeiten von Regierung und Parlament beseitigen. Letzteres würde den Sachzusammenhang zwischen Regierungs- und Parlamentswahl aufheben, der Bildung gegenläufiger Mehrheiten Vorschub leisten und auf die Wahlbeteiligung drücken, wäre also gleich in mehrfacher Hinsicht verfassungspolitisch schädlich. Als Ausweg böte sich eine differenzierte Lösung an: Scheidet der Ministerpräsident vor Ablauf der Hälfte der Wahlperiode aus, findet eine Neuwahl für die restliche Amtszeit statt. Endet die Amtszeit nach der Hälfte der Wahlperiode, übernimmt sein bisheriger Stellvertreter das Amt bis zur nächsten Wahl. Mit dieser Regelung würde einerseits erreicht, dass ein gewählter Ministerpräsident, ohne dass er sich einer weiteren Wahl stellen muss, für eine Mindestzeit von zweieinhalb Jahren amtieren kann. Andererseits trägt sie dem Umstand Rechnung, dass ein als Stellvertreter nachgerückter Ministerpräsident nicht über dieselbe Legitimation verfügt wie ein direkt gewählter Amtsinhaber.

Ein Problem der Nachrückerlösung könnte in dem Fall bestehen, dass ein Amtsinhaber in der zweiten Hälfte der Amtsperiode zurücktritt, nur um dem nachgerückten Stellvertreter, der ja vermutlich aus demselben parteipolitischen Lager stammt, bei der späteren Neuwahl eine bessere Ausgangsposition zu verschaffen. Im parlamentarischen System ist diese Form der Ämterübergabe durchaus üblich; unter den Bedingungen der Direktwahl wäre sie kaum zu legitimieren. Nicht definitiv bannen, aber doch vermindern ließe sich die Gefahr eines solchen Missbrauchs durch eine Amtszeitbegrenzung, wie sie in den präsidentiellen Regierungssystemen der USA und Lateinamerikas ausnahmslos vorgesehen ist, bezeichnenderweise aber nicht in den quasi-präsidentiell verfassten deutschen Kommunen. Die Wiederwahl des Ministerpräsidenten wäre danach nur einmal zulässig. In Verbindung mit der fünfährigen Amtsperiode und der oben dargestellten Nachfolgeregelung würde das bedeuten, dass eine Person immerhin bis zu zwölfeinhalb Jahren im Amt bleiben kann. Die Wahrscheinlichkeit, dass ein populärer Ministerpräsident nur aufgrund der Amtszeitbegrenzung weichen müsste, erscheint insofern gering.

\subsection{Bestellung des Kabinetts}

Auf der Bundesebene werden die Bundesminister laut Art. 64 Abs. 1 GG auf Vorschlag des Bundeskanzlers vom Bundespräsidenten ernannt und entlassen. Dieser Regel entsprechen acht der 16 Landesverfassungen; hier liegt das Ernennungs- und Entlassungsrecht sogar förmlich beim Ministerpräsidenten, der als Regierungschef die Funktion des Staatsoberhauptes mitübernimmt. Die anderen Bundesländer sehen eine Beteiligung des Landtags an der Regierungsbestellung vor. Damit knüpfen sie an eine Reihe europäischer Staaten an,

33 Analog sieht der 1967 in Kraft getretene XXV. Zusatz der US-Verfassung in seinem zweiten Abschnitt vor, dass ein während der Wahlperiode vom Präsidenten neu ernannter Vizepräsident der Bestätigung durch beide Häuser des Kongresses bedarf. Aktuell wurde diese Regelung zuletzt 1974, als mit Gerald Ford ein auf dem Ticket nicht (mit)gewählter Stellvertreter die Nachfolge des zurückgetretenen Präsidenten Richard Nixon antrat. 
deren parlamentarisch verfasste Regierungssysteme auf der nationalen Ebene vergleichbare Investiturabstimmungen vorsehen. Das Parlament muss danach dem Gesamtkabinett vor dessen Amtsantritt und in den meisten Fällen auch der Entlassung und Neu-Ernennung einzelner Minister zustimmen. Die Stadtstaaten Berlin und Bremen schreiben in ihren Verfassungen sogar die Einzelwahl der Senatoren vor, die nach demselben Verfahren auch abgewählt werden können. ${ }^{34}$

Weil die Personalentscheidungen bei der Regierungsbildung im parlamentarischen System ohnehin innerhalb und zwischen den Regierungsparteien ausgehandelt werden müssen, dürfte die förmliche Mitwirkung des Parlaments an der Regierungsbestellung in der Praxis keinen großen Unterschied ausmachen. ${ }^{35}$ Anders verhält es sich im präsidentiellen System, wo solche Bestätigungsrechte zu den „checks and balances“ gehören, die das System der strikten Gewaltentrennung bewusst durchbrechen. ${ }^{36}$ In den USA geht dies soweit, dass der Kongress sogar über die Organisationsgewalt im Bereich der Exekutive verfügt, der Präsident also ohne dessen Zustimmung keine Behörde einrichten kann. ${ }^{37}$ In den lateinamerikanischen Staaten bleiben den Parlamenten vergleichbare Mitwirkungsrechte versagt. Dafür (und im Unterschied zu den USA) verfügt eine Reihe von ihnen im Gegenzug über die Befugnis, einem Minister das Misstrauen auszusprechen und ihn - nötigenfalls auch gegen den Willen des Präsidenten - zu entlassen. Was die Bestätigung, Interpellation und mögliche Entlassung der Kabinettsmitglieder angeht, unterscheidet sich die präsidentielle Regierungsform somit nicht grundsätzlich von der parlamentarischen. Auch hier ist das Prinzip der individuellen Ministerverantwortlichkeit in vielen Verfassungen erhalten geblieben, wo es in der Praxis allerdings nur noch eine geringe Rolle spielt. Die kollektive Verantwortung der Regierung, die mit der Durchsetzung des Abberufungsrechts einherging, hat dazu geführt, dass die Minister im parlamentarischen System heute nicht mehr mit rechtlichen, sondern mit politischen Mitteln zur Demission gezwungen werden. Mangelnder Rückhalt beim Regierungschef und in der eigenen Partei ist dabei zumeist ein wichtigerer Rücktrittsgrund als der Druck der Opposition. ${ }^{38}$

Sollen die Bestätigungsrechte im US-System lediglich eine Vorkehrung gegen die Errichtung einer Günstlingswirtschaft durch den Präsidenten treffen, so hätten sie im Rahmen einer Verfassungsreform der Bundesländer auch die Funktion, den direkt gewählten Ministerpräsidenten in den politischen Willen der jeweiligen Landtagsmehrheit einzubinden. Um dieses Ziel zu erreichen, genügt eine Bestätigung des Gesamtkabinetts durch den Landtag

34 Bis zur 1996 in Kraft getretenen Verfassungsreform galt das auch für Hamburg. Seither muss die Bürgerschaft nur noch den Gesamtsenat und - auf Antrag des Ersten Bürgermeisters - die spätere Berufung einzelner Senatoren bestätigen (Art. 34 Abs. 2 Satz 2 HmbVerf).

35 Das zeigt zum Beispiel ein Vergleich der Praxis in Hamburg vor und nach der Reform. Vgl. Julia von Blumenthal, Freie und Hansestadt Hamburg: Das letzte Feierabendparlament, in: Siegfried Mielke / Werner Reutter, a.a.O. (Fn. 2), S. 216.

36 Laut Art. 2 Abschnitt 2 der US-Verfassung muss der Senat der Ernennung von Regierungsmitgliedern, Beamten, obersten Bundesrichtern und Botschaftern zustimmen. Zur Bedeutung dieser Bestimmung vgl. Ernst Fraenkel, Das amerikanische Regierungssystem. Eine politologische Analyse, Köln / Opladen 1960, S. 292 ff.

37 Vgl. Winfried Steffani, Parlamentarische und präsidentielle Demokratie, a.a.O. (Fn. 18), S. 66.

38 Vgl. Klaus von Beyme, Die parlamentarische Demokratie. Entstehung und Funktionsweise 1789 - 1999, Opladen 1999, S. 277 ff. 
(Investitur). ${ }^{39}$ Eine Bestätigung oder gar förmliche Wahl der einzelnen Minister - wie seinerzeit von Eschenburg für Baden-Württemberg vorgeschlagen ${ }^{40}$ - würde das Vorschlagsbeziehungsweise Bestellungsrecht des Ministerpräsidenten zu stark beschneiden. Der Ministerpräsident sollte die Minister (und Staatssekretäre) auch jederzeit entlassen dürfen, ohne dass das Parlament zustimmen muss. Eine schwierige Frage ist, ob das genauso für die Ernennung der neuen Minister gelten müsste. Bedürfen diese nicht der gesonderten Bestätigung durch den Landtag, könnte der Ministerpräsident den Zustimmungsvorbehalt zum Gesamtkabinett theoretisch unterlaufen, indem er dessen Zusammensetzung in seinem Sinne und gegen den Willen des Parlaments verändert. Des Weiteren stellt sich die Frage, was passiert, wenn das Parlament dem Ministerpräsidenten die Bestätigung des Kabinetts versagt. Eine Möglichkeit bestünde darin, die Nicht-Bestätigung an die Folge einer Parlamentsauflösung zu koppeln. Dies läge in der Logik des parlamentarischen Systems, wo das Scheitern einer Investiturabstimmung einem Misstrauensvotum gleichkommt. Die Auflösung müsste dabei nicht sofort erfolgen, sondern gegebenenfalls erst nach Scheitern der Bestätigung in einem zweiten oder dritten Anlauf.

Im Kontext des präsidentiellen Systems erscheint eine solche Lösung jedoch nicht zwingend. Um den Einigungsdruck zwischen Ministerpräsident und Landtag zu erhöhen, dürften zwei Vorkehrungen ausreichen: Zum einen führt die Verweigerung der Bestätigung dazu, dass die vorhandenen Minister und Staatssekretäre in ihren Ämtern verbleiben. Zum anderen muss der Ministerpräsident diese ohne Zustimmung des Landtags jederzeit austauschen können. Dem Landtag würde es unter diesen Bedingungen nichts nützen, wenn er durch Verweigern der Bestätigung ein aus seiner Sicht günstiger zusammengesetztes Kabinett im Amt halten würde (was in einer Konstellation des "divided government" theoretisch vorstellbar wäre). Umgekehrt müsste aber auch der Ministerpräsident Vorsicht walten lassen. Würde er die Minister reihum ersetzen, wäre der Landtag sicherlich nicht geneigt, ihn bei seinen Gesetzesvorschlägen anschließend zu unterstützen. Es gibt also genug Anreize für eine Einigung, so dass eine Nicht-Bestätigung des Kabinetts äußerst unwahrscheinlich sein dürfte.

Eine abweichende Regelung gilt für den vom Ministerpräsidenten bestimmten Stellvertreter. Da dieser dem Ministerpräsidenten gegebenenfalls nachfolgt, bedarf ein neuer Stellvertreter der gesonderten Bestätigung durch den Landtag (siehe oben).

In der Bestellung der Regierung liegt der Schlüssel für eine gedeihliche Zusammenarbeit des Ministerpräsidenten mit dem Landtag, auf dessen Wohlwollen er ja angewiesen bleibt, wenn er seine Gesetzesvorhaben verwirklichen will. Nur wenn seine eigene Partei zugleich über die absolute Mehrheit im Parlament verfügte (was zur Zeit nur in Hamburg der Fall ist), könnte es sich ein Regierungschef leisten, die anderen Fraktionen bei der Zusammenstellung des Kabinetts zu übergehen. So aber zwingt ihn das Bestätigungsrecht, seine Regierungsmannschaft auf eine parteipolitisch breite Basis zu stellen, die dauerhaft tragfähige legislative Mehrheiten hervorbringt. Ohne eine solche Koalitionsbildung ließe

39 Die Investiturabstimmung müsste, anders als die heutige Wahl der Ministerpräsidenten in den Landtagen, als offene Abstimmung stattfinden. Dies kann in der Geschäftsordnung geregelt werden. Zur Fragwürdigkeit der geheimen Abstimmung unter Demokratiegesichtspunkten siehe schon Winfried Steffani 1991 im ersten Band des Jahrbuch für Politik, wieder abgedruckt in: ders., Gewaltenteilung und Parteien im Wandel, a.a.O. (Fn. 18), S. 227 - 243. Jüngst dazu Frank Decker, a.a.O. (Fn. 21), S. 163 ff.

40 Vgl. Theodor Eschenburg, a.a.O. (Fn. 6), S. 66 f. 
sich ein konsistentes, auf innovative Problemlösungen abzielendes Regieren nicht gewährleisten.

\subsection{Legislative Kompetenzen und Ressourcenausstattung}

Um die Einbindung des Ministerpräsidenten und seiner Regierung in den Willen der Parlamentsmehrheit sicherzustellen, gäbe es institutionell einen weiteren Hebel, der der Logik des reinen Präsidentialismus im Grunde viel eher entspricht. Statt bei der Regierungsbildung und Zusammensetzung des Kabinetts anzusetzen, könnte man dem Ministerpräsidenten ein Vetorecht in der Gesetzgebung einräumen, das vom Landtag nur mit qualifizierter Mehrheit überstimmbar wäre. Dass diese Möglichkeit im Kontext der deutschen Verfassungsdiskussion völlig ausgeblendet wird ${ }^{41}$, ist einerseits merkwürdig, andererseits aber auch bezeichnend für die fortwirkende Prägung durch das parlamentarische System. Offenbar geht man hierzulande davon aus, dass die Regierung in Gestalt der Ministerialbürokratie eine so starke Position im Gesetzgebungsprozess behält, dass es einer zusätzlichen Waffe im Verhältnis zum Landtag nicht bedarf. Ablesbar ist dies zum Beispiel am Gesetzesinitiativrecht der Regierung, das natürlich auch nach Einführung der Direktwahl erhalten bliebe.

Unter dem Strich sprechen insofern mehr Gründe dafür, von einem Vetorecht abzusehen. Damit ist die Frage noch nicht beantwortet, ob die Aufwertung des Landtags, die man sich vom Übergang zum gewaltentrennenden Präsidentialismus erwartet, ohne Korrektur der bestehenden Ressourcenausstattung überhaupt vorstellbar wäre. Im gewaltenfusionierenden parlamentarischen System ist die Dominanz der Ministerialbürokratie bei der Gesetzesformulierung programmiert, weil die Mehrheit „ihrer" Regierung dieses Feld freiwillig überlässt. Auch wo die Vorlagen formal von den Fraktionen eingebracht werden, führen Regierungsbeamte in der Regel die Feder. Bei gleichgerichteten Mehrheitsverhältnissen wäre das wahrscheinlich auch in einem präsidentiellen System nicht viel anders. Entstammt der Ministerpräsident jedoch einem anderen politischen Lager als die Landtagsmehrheit, wäre deren legislativer Handlungsspielraum empfindlich beschnitten, wenn sie sich bei der Ausarbeitung der Gesetzesvorschläge ausschließlich auf die Regierungsbeamten stützen müsste. Eine zumindest partielle Umverteilung der Ressourcen zum Aufbau einer parlamentsseitigen „Gegenbürokratie“ erscheint von daher nach Einführung der Direktwahl unabweisbar. ${ }^{42} \mathrm{Um}$ sie herbeizuführen, bedarf es keiner verfassungsrechtlichen Normierung.

Bleiben die legislativen Strukturen unverändert, stellt sich aber auch nach einer solchen Ressourcenverschiebung die Frage, ob ein präsidentielles System unter den Bedingungen gegenläufiger Mehrheitsverhältnisse tatsächlich so problemlos funktionieren könnte, wie die Befürworter glauben machen wollen. Die Rivalität der Parteien, die in der Bundesrepublik über Jahrzehnte entstanden ist, würde ja nach einer Reform ebenso wenig über Nacht verschwinden wie die starke Ausstrahlung der Bundespolitik auf die Länder. Das Blockadeargument lässt sich insofern nicht einfach von der Hand weisen. Um zu verhindern, dass der Landtag der Regierung seinen Willen einseitig aufzwingt, scheint es deshalb sinnvoll, letz-

41 Auch in der ansonsten erschöpfenden Arbeit von Jan Backmann, a.a.O. (Fn. 10) findet das Vetorecht an keiner Stelle Erwähnung.

42 Vgl. Everhard Holtmann, a.a.O. (Fn. 8), S. 203 f. 
tere zumindest im Bereich der Budgethoheit mit einem Einspruchsrecht auszustatten. ${ }^{43}$ Dabei könnte man an die Bestimmung des Art. 113 GG anknüpfen, wonach Gesetze, die zu Ausgabeerhöhungen oder Einnahmeminderungen führen, der Zustimmung der Bundesregierung bedürfen. ${ }^{44}$ Diese Bestimmung, die in vergleichbarer Form in Großbritannien besteht, zeigt, dass Elemente der organschaftlichen Gewaltenteilung auch im parlamentarischen System präsent sind.

Ähnliches gilt für die Organisationsgewalt im Bereich der Regierung, die im parlamentarischen System des Grundgesetzes allein dem Bundeskanzler zugewiesen ist. Auch daran sollte man nach Einführung der Direktwahl festhalten, allerdings ergänzt um einen Zustimmungsvorbehalt des Landtags (analog zur Bestellung des Kabinetts), wie ihn zum Beispiel Art. 49 der Bayerischen Verfassung vorsieht.

\subsection{Vereinbarkeit beziehungsweise Unvereinbarkeit von Regierungsamt und Parlaments- mandat}

Die Vereinbarkeit von Regierungsamt und Parlamentsmandat ist ein weiteres Erkennungsmerkmal des parlamentarischen Systems. In Großbritannien ist die Ämterverbindung sogar gewohnheitsrechtlich vorgeschrieben, also nicht nur erlaubt. Sie geht auf den historischen Entstehungshintergrund des Parlamentarismus zurück: Das sich vom Monarchen allmählich emanzipierende Parlament wollte von diesem die Regierungsmitglieder nicht mehr vorgesetzt bekommen, sondern sie aus den eigenen Reihen rekrutiert wissen. Mit dem vollständigen Übergang der politischen Macht auf die Regierung hat sich diese ursprüngliche Zweckbestimmung erübrigt. Die in präsidentiellen Regierungssystemen übliche Unvereinbarkeit lässt sich insofern auch im Rahmen der parlamentarischen Regierungsform verwirklichen, wie die Verfassungen Hamburgs und Bremens oder - im nationalen Rahmen Frankreichs und der Niederlande beweisen.

Im präsidentiellen System ist das Verbot der Ämterverbindung durch die gewaltentrennende Grundstruktur funktionslogisch vorgegeben. Das Parlament versteht sich hier im Ganzen als Kontrollorgan gegenüber der Regierung, mit der es sich auch die legislative Macht teilt. Die Kontrollfunktion würde zu einer Farce, wenn sich die Kontrolleure selbst kontrollieren müssten. In parlamentarischen Systemen, in denen Minister zugleich Abgeordnete sind, ist in Bezug auf die Regierungstätigkeit genau das der Fall. Hinzu kommt, dass die Minister ihr Mandat schon aus Zeitgründen gar nicht ausüben können und - von der

43 Im präsidentiellen System der USA ist es genau umgekehrt: Hier erstreckt sich das Vetorecht des Präsidenten gegenüber dem Kongress nicht auf die Haushaltsgesetze. Vgl. Ernst Fraenkel, a.a.O. (Fn. 33), S. 322.

44 Vgl. Theodor Eschenburg, a.a.O. (Fn. 6), S. 72. Neben der baden-württembergischen (Art. 82) hat auch die sächsische Landesverfassung (Art. 97) diese Bestimmung übernommen. Die hessische (Art. 119) und nordrhein-westfälische Landesverfassung (Art. 67) sehen sogar ein allgemeines Einspruchsrecht der Regierung gegen Gesetzesbeschlüsse des Landtags vor. In den Stadtstaaten Bremen und Hamburg wurden vergleichbare Regelungen gestrichen. Vgl. Stefan Malorny, Exekutive Vetorechte im deutschen Verfassungssystem. Eine systematische Darstellung und kritische Würdigung unter besonderer Berücksichtigung der rechtshistorischen Herausbildung sowie der institutionellen Einpassung in die parlamentarischen Demokratiestrukturen Deutschlands und Europas, Göttingen 2011. 
Teilnahme an Abstimmungen abgesehen - auch nicht müssen, weil sie in ihrem Regierungsamt voll ausgelastet sind.

Unter den Bedingungen des hiesigen Verhältniswahlsystems mit Listenwahl wäre es technisch problemlos möglich, die bestehende Praxis der Ämterverbindung abzuschaffen. Gewählte Abgeordnete, die ihr Mandat nicht antreten, würden dann genauso wie vorzeitig ausgeschiedene Abgeordnete durch Nachrücker auf der Liste ersetzt. Dies gilt auch für die direkt gewählten Abgeordneten, die nicht über die Listen in das Parlament eingezogen sind.

Ein wichtiger Funktionsgesichtspunkt, der für die Beibehaltung der Vereinbarkeit von Regierungsamt und Mandat spricht, bleibt allerdings. Wird die Ämterverbindung verboten, würde die personelle Rekrutierungsbasis sowohl für die Regierungen als auch für die Parlamente schmaler. Weil die Inkompatibilität nicht im Vorfeld wirkt, könnten Politiker mit Ambitionen auf ein Ministeramt als Abgeordnete zwar immer noch kandidieren, sie hätten aber keine Möglichkeit, auf einen Abgeordnetensitz zurückzukehren, wenn sie als Minister vorzeitig aus dem Amt scheiden. Dieses Problem stellt sich auch unter präsidentiellen Vorzeichen, zumal wenn die anzustrebende Regierungsform - wie hier vorgeschlagen - in Richtung einer präsidentiell-parlamentarischen Mischform tendiert.

Die Übernahme der in Hamburg und Bremen bestehenden Regelung, das Mandat für die Dauer der Ministertätigkeit ruhen zu lassen, wäre ein möglicher Kompromiss. ${ }^{45}$ Dies wird auch in einer Reihe von präsidentiellen Systemen in Lateinamerika so praktiziert. ${ }^{46}$ Gegen das ruhende Mandat spricht, dass es die nachrückenden Abgeordneten zu Parlamentariern zweiter Klasse machen würde, indem diese ihren Sitz auch gegen den eigenen Willen wieder verlieren könnten. Dies erscheint auch mit Blick auf das verfassungsrechtliche Gebot der gleichen Wahl problematisch. In der Abwägung sprechen daher mehr Argumente für eine strikte Inkompatibilitätsregel. ${ }^{47}$

\section{Schlussbemerkung: Welche Chancen hat die Reform?}

Wer den Direktwahlvorschlag als unrealistisch abtut, übersieht, dass die Reichweite der Verfassungsreformen in den Ländern durch die neu eingerichteten Verfahren der direkten

45 Zur Weimarer Zeit in sechs der 18 Landesverfassungen verankert, wurde das „ruhende Mandat“ nach der Neugründung der Länder auch in Rheinland-Pfalz und - später - in Hessen übernommen. Gegen die Verfassungsgemäßheit der Regelung regten sich jedoch bald Bedenken, die in der Nichtigerklärung des „ruhenden Mandats“ durch den Hessischen Staatsgerichtshof im Jahre 1977 kulminierten. Rheinland-Pfalz und Hessen nahmen dies zum Anlass, die Rückkehrmöglichkeit von Regierungsmitgliedern in das Parlament abzuschaffen. In den beiden Stadtstaaten hat das „ruhende Mandat“ dagegen bis heute Bestand. Vgl. Kersten Rosenau, Das „Ruhende Mandat“- die Hansestädte und das Grundgesetz, in: ZParl, 19. Jg. (1988), H. 1, S. 35 - 43.

46 Selbst in den USA kann von einer strikten Durchhaltung der Gewaltenteilung keine Rede sein. Art. 1 Abschnitt 6 der Verfassung bestimmt, dass Senatoren und Abgeordnete für die Zeit ihrer Tätigkeit nicht in Diensten des Bundes stehen dürfen. Da die USA kein Kabinett im verfassungsrechtlichen Sinne kennen, die „Minister“ als Berater des Präsidenten mithin keine öffentlichen Ämter bekleiden, sondern den Status von Privatpersonen haben, wäre die Kabinettsmitgliedschaft eines Abgeordneten damit theoretisch durchaus zulässig. In der Verfassungspraxis hat sich die Inkompatibilität dennoch vollständig durchgesetzt. Von dieser Regel ausgenommen werden muss allerdings der Vizepräsident, der als Vorsitzender des Senats zugleich förmlich in das Parlament eingebunden ist. Vgl. Winfried Steffani, Parlamentarische und präsidentielle Demokratie, a.a.O. (Fn. 18), S. 73.

47 Vgl. Jan L. Backmann, a.a.O. (Fn. 10), S. 352 ff. 
Demokratie enorm zugenommen hat. Damit ist zugleich die Chance gewachsen, institutionelle Veränderungen jenseits der eingefahrenen Interessen und Pfade anzustoßen.

Das hier entworfene Modell der Direktwahl der Ministerpräsidenten weicht von dem auf Bitte der bayerischen ÖDP entworfenen Reformvorschlag in einigen Punkten ab. Dies hängt zum einen mit bayerischen Besonderheiten zusammen, denen Rechnung zu tragen war, um die Verfassungsänderungen auf das Nötige zu beschränken („minimalinvasiver“ Entwurf). Zum anderen mussten die nicht immer deckungsgleichen Vorschläge der Experten und Initianten ausbalanciert werden. Unterschiedlich geregelt ist zum Beispiel die Nachfolge, wo - anknüpfend an vergleichbare Bestimmungen im bayerischen Gemeinde- und Landkreiswahlgesetz - eine komplette Neuwahl auch für die Dauer der neuen Wahlperiode vorgesehen ist, wenn der Ministerpräsident im letzten Jahr seiner Amtszeit ausscheidet. (Scheidet er vorher aus, wird für den Rest der Amtsperiode neu gewählt.) Eine Amtszeitbegrenzung ist nicht beabsichtigt. Zudem soll die Abwahl des Regierungschefs nur auf Antrag des Volkes möglich sein und die Selbstauflösung des Landtag ebenso wie die plebiszitäre Auflösung erhalten bleiben. Die vom Verfasser vorgeschlagenen „checks and balances“ - Zustimmungsrecht des Landtags zum Gesamtkabinett und zur Abgrenzung der Geschäftsbereiche, Vetorecht der Regierung gegenüber finanzwirksamen Gesetzesbeschlüssen - wurden nicht aufgegriffen, um die „Reinheit“ der Gewaltenteilung sicherzustellen.

Festzuhalten ist: Die Abkehr vom parlamentarischen System ist längst keine bloße theoretische Denkmöglichkeit mehr. Statt den Vorschlag reflexhaft zurückzuweisen oder ihn mit polemischen Bemerkungen zu diskreditieren, wie es in den ersten Stellungnahmen von CSU- und SPD-Seite anklang ${ }^{48}$, sollten sich die anderen Parteien auf eine faire Debatte um das Für und Wider der Direktwahl einlassen. Gerade die CSU wäre gut beraten, dem Vorhaben nicht mit derselben Arroganz zu begegnen wie seinerzeit der - ebenfalls von der ÖDP initiierten - Abschaffung des bayerischen Senats. Damals hatte die kleine Partei bekanntlich das bessere Ende für sich. Da die Volksbegehrenshürde in Bayern relativ hoch liegt und das zeitgleich laufenden Volksbegehren für die Abschaffung der Studiengebühren das öffentliche Interesse von der Initiative stark abzieht ${ }^{49}$, werden es die Initiatoren schwer haben, den angestrebten Volksentscheid zu erreichen. Dies gilt zumal, als es die ÖDP nicht darauf anlegt, in dieser Frage den Schulterschluss mit den Freien Wählern zu suchen. Der eigentlichen Sache erweist sie damit einen Bärendienst, denn dass die Bürger in einem Volksentscheid, wenn sie die Wahl hätten, mehrheitlich für die Einführung der Direktwahl stimmen würden, erscheint schon jetzt relativ gewiss.

Es ist also an der Zeit, dass sich die Politikwissenschaft mit dem Für und Wider einer solchen Reform stärker beschäftigt.

48 Während der frühere CSU-Fraktionschef Georg Schmid davor warnte, den Landtag durch den Entzug der Wahlfunktion seiner „entscheidenden Kraftquelle“ zu berauben, verstieg sich der SPDAbgeordnete und Verfassungsexperte Franz Schindler sogar zu der Behauptung, bei dem Vorschlag handele es sich um eine „Schnapsidee von Parlamentsverächtern“. Beides zeugt von einer bemerkenswerten Unkenntnis der Zusammenhänge.

49 Innerhalb einer Frist von zwei Wochen müssen sich zehn Prozent der Wahlberechtigten, das sind in Bayern rund 950.000 Bürger, auf ein Amt begeben und in die dort ausliegenden Listen für das Volksbegehren eintragen. 